\title{
The role of obesity in cancer development
}

\author{
Jan Goedeke, MD*, Oliver J. Muensterer, MD, PhD
}

Being overweight has been a long-known peril to health, and scientists were able to show a relationship between body fat and cancer years ago. Of course, not every obese individual will inevitably develop cancer, but recent scientific studies show that excessive body fat has an impact on a much broader spectrum of cancers than previously thought ${ }^{[1]}$. This applies to adults as well as children and adolescents.

In 2015, the Organisation for Economic Co-operation and Development (OECD) reported that already $>50 \%$ of adults and nearly $30 \%$ of teenagers in 34 member countries were considered overweight (body mass index, BMI $\geq 25 \mathrm{~kg} / \mathrm{m}^{2}$ body surface area), or even obese (BMI $\geq 30 \mathrm{~kg} / \mathrm{m}^{2}$ body surface area ${ }^{[2,3]}$. The tendency increased gradually in all countries over a period of 25 years (1990-2015). We therefore have to expect steadily rising numbers of cancers worldwide solely due to obesity in the future.

A population-based study using BMI and cancer incidence data from the GLOBOCAN project estimated that, in 2012 in the United States, about 28,000 new cases of cancer in men $(3.5 \%)$ and 72,000 in women $(9.5 \%)$ were due to overweight or obesity $^{[4]}$. The percentage of cases attributed to overweight or obesity varied widely for different cancer types but was as high as $54 \%$ for gallbladder cancer in women and $44 \%$ for esophageal adenocarcinoma in men.

The International Agency for Research on Cancer (IARC) as part of the World Health Organization (WHO) in 2016 reported an increased risk of cancer for at least 13 cancer types [colon cancer, esophageal cancer, renal carcinoma, uterine cancer, breast cancer (during and after menopause; also in men), liver cancer, pancreatic cancer, gall bladder cancer, ovarian cancer, gastric cancer, thyroid cancer, multiple myeloma, and meningioma $]^{[1]}$. For some of these cancers, the experts even found a dose-response relationship, implying that the risk of cancer increases with $\mathrm{BMI}^{[1]}$.

Department of Pediatric Surgery, University Medical Center of the Johannes Gutenberg-University Mainz, Mainz, Germany

This manuscript has been peer reviewed.

Sponsorships or competing interests that may be relevant to content are disclosed at the end of this article.

${ }^{*}$ Corresponding author. Address: Department of Pediatric Surgery, University Medical Center of the Johannes Gutenberg-University Mainz, Langenbeckstr. 1, Mainz 55131, Germany. Tel.: + 496131 17-2034; fax: + 496131 17-6523. E-mail address: jan.goedeke@unimedizin-mainz.de (J. Goedeke).

Copyright (C) 2019 The Authors. Published by Wolters Kluwer Health, Inc. on behalf of IJS Publishing Group Ltd. This is an open access article distributed under the

Creative Commons Attribution License 4.0 (CCBY), which permits unrestricted use, distribution, and reproduction in any medium, provided the original work is properly cited.

International Journal of Surgery Oncology (2019) 4:e77

Received 15 August 2019; Accepted 9 September 2019

Published online 3 October 2019

http://dx.doi.org/10.1097/IJ9.0000000000000077
Currently, there are many theories that could explain the increased incidence of cancer in obesity. The preponderance of the evidence suggests that a combination of different factors might be responsible. However, it should be reiterated that there is no direct link between obesity and the development of cancer.

On the one hand, obesity seems to cause a general hormonal imbalance including hyperinsulinemia and an increase in insulinlike growth factors, as well as sex hormones. In addition, hyperplastic and hypertrophic white adipose tissue (especially visceral adipose tissue) acts as an independent active endocrine organ releasing immunologically active adipokines and other hormones. These hormonal imbalances support cell growthpromoting processes ${ }^{[5]}$. On the other hand, obesity is associated with a state of low-grade chronic inflammation. Insulin resistance and the metabolic syndrome are associated with higher circulating concentrations of inflammation-related markers, including leptin, interleukin-6, and tumor necrosis factor, many of which have been shown to enhance tumor growth. Chronic inflammation is a well-known, obesity independent critical component of tumor development and progression. Many cancers arise from sites of infection, chronic irritation, and inflammation ${ }^{[6]}$.

Obesity is only one of many important triggers of low-grade chronic inflammation, whereas per current literature there is no study published, that clearly shows that chronic inflammation is inversely related to the development of obesity.

In addition, a further mechanism that suppresses the eradication of neoplastic cells is immune paralysis, which is also due to chronic inflammation. Not least, preclinical studies showed that adipocytic progenitor cells contribute to a tumor-promoting microenvironment ${ }^{[5]}$ as well.

Controlled diet and lifestyle adjustments can lower the risk of cancer. It would be naive to believe that through a healthy diet and regular physical exercise, however, cancer development were to be prevented entirely ${ }^{[7,8]}$.

Could losing weight reduce the risk of cancer? So far, this has not been proven, although some preliminary study results suggest it ${ }^{[9,10]}$.

However, the above results should still be interpreted with caution, as the published studies were too heterogenous in their design, the populations studied and different lengths of followup, so that it is too early at the moment, to make definitive recommendations. Reducing the excess weight once acquired, however, is difficult for many people. For most patients, making sure to at least not gain further weight is the first step. Likewise, people with normal weight should at least try to maintain it ${ }^{[1]}$.

Bariatric or metabolic surgical interventions have shown some initial beneficial effect for primary prevention of cancer, although it is far too early to draw definitive conclusions ${ }^{[11,12]}$.

Nevertheless, weight reduction seems to provide some degree of primary prophylaxis not only concerning metabolic and cardiovascular disease, but also for developing a wide array of neoplasms ${ }^{[13]}$. 


\section{Conclusions}

The increasing incidence of obesity is one of the biggest challenges facing our society's future on a global scale. In addition to other major issues, there is convincing evidence that obesity increases the risk for many types of cancer, most likely due to general hormonal imbalance and chronic low-grade inflammation processes. Nevertheless, tumor development is a multifactorial process and simple obesity does not directly cause tumor development. Controlled diet and lifestyle adjustments can lower the risk of selected cancer types as well as metabolic surgical interventions. Nevertheless, it is far too early to draw definitive conclusions, and far more research is needed to answer the many still remaining questions, particularly on the effect of weight loss programs and surgical interventions. Also, it is unclear to what extent obesity in childhood and adolescence plays in the subsequent risk of cancer in adults.

\section{References}

[1] Lauby-Secretan B, Scoccianti C, Loomis D, et al. International Agency for Research on Cancer Handbook Working Group. Body fatness and cancer-viewpoint of the IARC Working Group. N Engl J Med 2016;375: 794-8.

[2] Organisation for Economic Co-operation and Development. Health at a glance 2017: risk factors for health. Available at: www.oecd-ilibrary.org/ docserver/health_glance-2017-en.pdf?expires $=1565006966 \&$ id=id\&acc name $=$ guest $\&$ checksum=FF90A364CA97D12D4EBE9C58B73836D0. Accessed August 25, 2019.

[3] Organisation for Economic Co-operation and Development. Obesity update. Available at: www.oecd.org/els/health-systems/Obesity-Update2017.pdf. Accessed August 25, 2019.

[4] Arnold M, Pandeya N, Byrnes G, et al. Global burden of cancer attributable to high body-mass index in 2012: a population-based study. Lancet Oncol 2015;16:36-46.

[5] Khandekar MJ, Cohen P, Spiegelman BM. Molecular mechanisms of cancer development in obesity. Nat Rev Cancer 2011;11:886-95.

[6] Coussens LM, Werb Z. Inflammation and cancer. Nature 2002;420: 860-7.

[7] Schüz J, Espina C, Villain P, et al. Working Groups of Scientific Experts. European Code against Cancer 4th Edition: 12 ways to reduce your cancer risk. Cancer Epidemiol 2015;39(suppl 1):S1-10.

[8] Minozzi S, Armaroli P, Espina C, et al. European Code against Cancer 4th Edition: Process of reviewing the scientific evidence and revising the recommendations. Cancer Epidemiol 2015;39(suppl 1):S11-19.

[9] Byers T, Sedjo RL. Does intentional weight loss reduce cancer risk? Diabetes Obes Metab 2011;13:1063-72.

[10] Anderson AS, Key TJ, Norat T, et al. European code against cancer 4th edition: obesity, body fatness and cancer. Cancer Epidemiol 2015; 39(suppl 1):S34-45.

[11] Kwak M, Mehaffey JH, Hawkins RB, et al. Bariatric surgery is independently associated with a decrease in the development of colorectal lesions. Surgery 2019;166:322-6.

[12] Mackenzie H, Markar SR, Askari A, et al. Obesity surgery and risk of cancer. Br J Surg 2018;105:1650-7.

[13] Dietrich A, Aberle J, Wirth A, et al. Clinical Practice Guideline: obesity surgery and the treatment of metabolic diseases. Dtsch Arztebl Int 2018; 115:705-11. 